Review

\title{
OVERLAPS IN THE PATHOGENESIS OF ROSACEA AND ATHEROSCLEROSIS
}

\author{
Aleksejs Zavorins ${ }^{1, \#}$, Jūlija Voicehovska ${ }^{2}$, Jānis K̦īsis ${ }^{1}$, and Aivars Lejnieks ${ }^{2}$ \\ ${ }^{1}$ Department of Infectology and Dermatology, Rīga Stradiṇš University, 3 Linezera Str., Rīga, LV-1006, LATVIA \\ 2 Department of Internal Diseases, Rīga Stradiṇš University, 13 Pilsoṇu Str., Rīga, LV-1002, LATVIA \\ \# Corresponding author, aleksejs.zavorins@gmail.com
}

Contributed by Aivars Lejnieks

\begin{abstract}
Rosacea is a chronic inflammatory skin disease characterised by transient or persistent erythema, telangiectasia, papules, and pustules that predominantly involve central regions of the face. Recent studies have shown a possible clinical association between rosacea and cardiovascular diseases (CVDs). Rosacea and atherosclerosis are both known to have alterations in the innate immune system, enhanced oxidative and endoplasmic reticulum stress. The aim of this review is to delve deep into the pathogenesis of rosacea and atherosclerosis to uncover possible pathogenic overlaps between these chronic inflammatory diseases.
\end{abstract}

Key words: rosacea, atherosclerosis, Toll-like receptor 2, LL-37, endoplasmic reticulum stress, oxidative stress.

\section{INTRODUCTION}

Rosacea is a chronic inflammatory skin disease with a prevalence that ranges from $0.9-22 \%$ in Europe. Northern countries tend to have higher rosacea prevalence (Spoendlin et al., 2012). Characteristic features of rosacea include transient or persistent erythema and telangiectasia that involve facial convexities. Inflammatory papules and pustules are also not uncommon. Certain patients develop an ocular disease or fibrotic changes of the nasal skin known as rhinophyma (Two et al., 2015). Patients can be divided into four clinical subtypes: erythematotelangiectatic (ET), papulopustular (PP), phymatous, and ocular (Wilkin et al., 2002; Two et al., 2015). The symptoms are exacerbated by trigger factors, such as ultraviolet (UV) radiation, temperature extremes, alcohol consumption, emotional stress, spicy food, and hot beverages (Steinhoff et al., 2016).

Recent studies have shown a possible association between rosacea and cardiovascular diseases (CVDs). According to the World Health Organization, CVDs cause $31 \%$ of all deaths, thus being the leading cause of deaths worldwide and in Latvia (Mendis et al., 2015). Atherosclerosis is an inflammatory disease of the coronary, cerebral, and peripheral arteries that causes progressive obstruction of these vessels due to the accumulation of lipids and extracellular matrix remodelling with a possible eventual thrombosis. It is the principal cause of the CVDs (Hansson and Libby, 2006).

Patients with rosacea tend to have high levels of total cholesterol, low density lipoproteins (LDL) and C reactive pro- tein (CRP), as well as a positive history of smoking, alcohol consumption, and premature CVDs in a first-grade relative (Duman et al., 2014). Coronary artery disease and hypertension have also been associated with rosacea in a Taiwanese nation-wide study (Hua et al., 2015). Cardiovascular risk factors such as alcohol abuse, diabetes, arterial hypertension, and smoking were also associated with rosacea in a Danish-register based study. However, the same study pointed out that the adverse cardiovascular outcomes, such as myocardial infarction, ischemic stroke, haemorrhagic stroke, major adverse cardiovascular events and all-cause mortality, were not seen more frequently in patients with rosacea (Egeberg et al., 2016). Authors acknowledge that only patients who have been diagnosed with rosacea in a hospital-based setting have been enrolled, and no division was made between different rosacea subtypes. This information could be crucial for the interpretation of the results, because a recent article noted that patients with PP subtype have a significantly higher cardiovascular risk according to the SCORE method, in comparison to the ET subtype (Akin Belli and Altun, 2017).

The aim of this review is to delve deep into the pathogenesis of rosacea and atherosclerosis to uncover possible pathogenic overlaps between these chronic inflammatory diseases. Both diseases are known to have alterations in the innate immune system, oxidative and endoplasmic reticulum stress. First, the authors of this review will present a brief overview of the pathogenesis of rosacea and atherosclerosis. Afterwards, the role of these pathogenetic mecha- 
nisms in each of the diseases will be elaborated, and finally, the common components of these diseases will be described. The data is summarised in Table 1 ( $\mathrm{Li}$ and Förstermann, 2014; Pateras et al., 2014; Two et al., 2015; Steinhoff et al., 2016).

\section{OVERVIEW OF THE PATHOGENESIS OF ROSACEA AND ATHEROSCLEROSIS}

Overview of the rosacea pathogenesis. Rosacea is characterised by an inflammation of the facial skin that is aggravated by the aforementioned environmental and endogenous triggers. Innate immunity is the first line of defence against microorganisms. It is also responsible for an appropriate response to environmental stimuli, including microorganisms, $\mathrm{UV}$ radiation, and other physical or chemical damage. In comparison to the adaptive immunity, innate immune response is relatively less specific, more rapid, when encountering unknown threats, and is considered phylogenetically more ancient (Litman et al., 2005). Dysregulation of innate immunity is currently viewed as an important aspect of the pathogenesis of rosacea. It is thought that activation of the innate immune system, through Toll-like receptor 2 (TLR2), by the rosacea triggers leads to controlled release of cytokines and certain antimicrobial peptides (AMPs)
(Yamasaki and Gallo, 2009). Toll-like receptor 2 (TLR2), cathelicidin antimicrobial peptide (CAMP), and serine protease kallikrein 5 (KLK5) are all part of the innate immunity, and the baseline levels of all of these molecules are increased in the facial skin of rosacea patients. TLR2 is known to enhance expression of KLK5. This serine protease splits CAMP into active peptides that have antimicrobial, pro-inflammatory, and angiogenetic features (Yamasaki et al., 2007; Steinhoff et al., 2013; Two et al., 2015). Matrix metalloproteinases (MMPs), particularly MMP-2 and MMP-9, also contribute by activating KLK5 and remodelling extracellular matrix (ECM) (Two et al., 2015).

Transient receptor potential (TRP) vanilloid and ankyrin channels are upregulated in rosacea and can be activated by emotional stress, heat and spicy food, resulting in transient erythema (flushing) and stinging sensation (Two et al., 2015).

All this leads to non-specific histological features. Vasodilation in the papillary dermis and low-grade perivascular lymphohistiocytic infiltration is the hallmark of ET rosacea. PP rosacea additionally demonstrates significant perivascular and perifollicular infiltrate in the dermis that consists of lymphocytes, plasma cells, and neutrophils (Lee et al., 2016).

Table 1

\begin{tabular}{|c|c|c|}
\hline \multirow[t]{2}{*}{ Overlapping feature } & \multicolumn{2}{|l|}{ Pathogenetic role } \\
\hline & Rosacea & Atherosclerosis \\
\hline \multirow[t]{2}{*}{ Raised LDL levels and OxLDL } & \multicolumn{2}{|c|}{$\begin{array}{l}\text {-LDL overload promotes ER stress } \\
\text {-LDL induce angiogenesis via TLR2 stimulation - oXLDL induce secretion of MMPs and ECM remodelling }\end{array}$} \\
\hline & - & $\begin{array}{l}\text { - scavenging of OxLDL activates NF- } \kappa \mathrm{B} \text { pathway and } \\
\text { expression of MCP-1 and VCAM-1, which attracts } \\
\text { monocytes, and leads to their transformation into foam } \\
\text { cells }\end{array}$ \\
\hline \multirow[t]{2}{*}{ Increased expression of TLR2 } & \multicolumn{2}{|l|}{$\begin{array}{l}\text { - activate the pro-inflammatory NF- } \kappa \mathrm{B} \text { pathway } \\
\text { - stimulates production of ROS by NADPH oxidase }\end{array}$} \\
\hline & $\begin{array}{l}\text { - increases KLK5 activity, which cleaves CAMP into } \\
\text { active peptides }\end{array}$ & $\begin{array}{l}\text { - in vivo promotes development of an atheroma } \\
\text { - promotes ER stress and apoptosis of endothelial cells } \\
\text { in the presence of neutrophils }\end{array}$ \\
\hline \multirow[t]{2}{*}{ Increased expression of CAMP/LL-37 } & \multicolumn{2}{|c|}{ LL-37 is capable of inducing angiogenesis, liberation of chemokines and cytokines } \\
\hline & $\begin{array}{l}\text { - in vivo injection of CAMP fragments causes develop- } \\
\text { ment of rosacea-like dermatitis }\end{array}$ & $\begin{array}{l}\text { - LL-37 is thought to promote atheroma expansion by } \\
\text { inducing growth of vasa vasorum }\end{array}$ \\
\hline \multirow[t]{2}{*}{ Oxidative stress } & \multicolumn{2}{|l|}{$\begin{array}{l}\text { - promotes ER stress } \\
\text { - ROS activate TLR2 }\end{array}$} \\
\hline & - ROS promote transient erythema by activating TRPs & $\begin{array}{l}\text { - promotes endothelial dysfunction } \\
\text { - produces oxLDL }\end{array}$ \\
\hline \multirow[t]{2}{*}{ Endoplasmic reticulum stress } & \multicolumn{2}{|l|}{$\begin{array}{l}\text { - indirectly activates NF- } \kappa \mathrm{B} \text { pro-inflammatory pathway } \\
\text { - promotes oxidative stress }\end{array}$} \\
\hline & $\begin{array}{l}\text { - enhances expression of TLR } 2 \text { and activates it } \\
\text { - induces expression of the CAMP gene } \\
\text { - stimulates TRP channels causing transient erythema in } \\
\text { response to heat }\end{array}$ & $\begin{array}{l}\text { - induces expression of apoptosis-related genes and the } \\
\text { expansion of the necrotic core of the atheroma }\end{array}$ \\
\hline
\end{tabular}

Raised low-density lipoproteins (LDL) and their oxidised forms (OxLDL), increased Toll-like receptor 2 (TLR2) and cathelicidin antimicrobial peptide expression, oxidative and endoplasmic reticulum (ER) stress are all overlapping features of rosacea and atherosclerosis pathogenesis. On the right side of the table their impact on the development of both diseases is demonstrated. Abbreviations: Nuclear factor kappa B (NF- $\kappa \mathrm{B}$ ), matrix metalloproteinases (MMPs), monocyte chemotactic protein-1 (MCP-1), vascular cell adhesion molecule (VCAM-1), reactive oxygen species (ROS), kallikrein serine protease 5 (KLK5). 
Overview of the atherosclerosis pathogenesis. Historically, atherosclerosis was seen as a mere obstruction of the arteries due to the accumulation of lipids in the arterial wall. Nowadays, atherosclerosis is known to be a chronic inflammatory disease. It involves highly specific intercellular interactions. Genetic predisposition, as well as the presence of traditional risk factors - diabetes mellitus, hypertension, dyslipidemia and smoking - is crucial for the development of the atherosclerotic plaque (Pant et al., 2014; Förstermann et al., 2017). Under these circumstances, activation of the endothelial cells and the subsequent attraction of monocytes and T lymphocytes takes place. Monocytederived macrophages migrate to the sub-endothelial space and ingest oxidised low-density lipoproteins (oxLDL), thus turning into foam cells. OxLDL are also taken up by endothelial and vascular smooth muscle cells (VSMCs) where they induce secretion of pro-inflammatory cytokines. VSMCs proliferate and produce extracellular matrix (ECM) components forming an atheroma. The atheroma enlarges and may obstruct the arterial blood flow leading to ischemia or even a myocardial infarction (Li and Förstermann, 2014; Pateras et al., 2014). Atheromatous tissue necrosis, minor damages to the endothelial cells and the endothelial dysfunction promote contact of the coagulation factors in the blood stream with the thrombogenic lipid core of the atheroma. Endothelial dysfunction is a broad term that describes a state, in which damaged endothelium promotes inflammation, coagulation, attraction of platelets, and vasoconstriction (Pant et al., 2014; Förstermann et al., 2017). Activated platelets play a role in the formation of a thrombus by aggregating and by secreting vasoactive chemokines (e.g. thrombospondin, platelet-activating factor) (Badimon et al., 2012).

\section{CATHELICIDIN ANTIMICROBIAL PEPTIDE (CAMP)}

CAMP is a pro-peptide normally produced in response to certain microbial triggers. Serine proteases, such as KLK5 cleave CAMP into smaller peptide fragments. These peptides are functionally active forms of CAMP. LL-37 is the most recognised of them. It has a direct antimicrobial function (Reinholz et al., 2012).

Cathelicidin antimicrobial peptide and rosacea. In case of rosacea, baseline CAMP levels are constantly elevated (Yamasaki and Gallo, 2009). Upon activation LL-37 is capable of inducing angiogenesis, liberation of chemokines and cytokines. LL-37 possesses chemotactic capabilities (Yamasaki et al., 2007; Yamasaki and Gallo, 2009; Steinhoff et al., 2013). Injection of cleaved peptide fragments of the CAMP cause development of rosacea-like dermatitis in mouse skin (Yamasaki et al., 2007).

Not only that the expression of KLK5 is enhanced in rosacea skin, but its functions are also altered. In case of rosacea KLK5 cleaves CAMP into smaller fragments than in healthy individuals, thus their functions may also differ (Yamasaki et al., 2007; Two et al., 2015).
Cathelicidin antimicrobial peptide and atherosclerosis. Interestingly, enhanced baseline levels of LL-37 antimicrobial peptide have been found not only in the facial skin of rosacea patients, but also in the atherosclerotic arteries (Edfeldt et al., 2006). Elevated LL-37 plasma levels have been associated with cardiovascular risk factors such as increased systolic blood pressure, triglycerides, and fasting glucose levels (Benachour et al., 2009). LL-37 promotes atherosclerosis by its angiogenetic function. Vasa vasorum is a network of smaller blood vessels that supply walls of the large arteries and veins. Their ingrowth into the atheroma could promote its growth (Jaipersad et al., 2013; Salvado et al., 2013;).

Vitamin D enhances CAMP expression. It is not fully understood, what exactly causes the enhanced expression of CAMP. However, it is thought that the activation of vitamin D pathway by the UV light is one of the possible mechanisms in rosacea. UV is known to exacerbate rosacea and it usually involves sun exposed facial areas (Park et al., 2011; Steinhoff et al., 2013). Vitamin D3 predominantly suppresses adaptive immunity, whereas innate immunity mechanisms such as cathelicidin expression in wounds and infections are activated. Vitamin D3 response element (VDRE) is located in the promoter region of the cathelicidin gene in keratinocytes. Therefore, induction of CAMP gene expression by UV may be due to the increased production of vitamin D (Dombrowski et al., 2010). Plasma levels of LL-37 directly correlate with the vitamin D3 plasma levels (Honda et al., 2014), as well as individuals with rosacea have relatively high levels of vitamin D3 (Ekiz et al., 2013) On the other hand, there is a vast amount of evidence that low vitamin D3 levels promote atherosclerosis (Kassi et al., 2013). Paradoxically, rosacea is most prevalent in individuals with fair skin of European descent, in which vitamin D deficiency is common due to their geographical location. That is why an alternative vitamin D-independent mechanism to promote CAMP expression has been proposed (Melnik, 2014; Melnik, 2016). LL-37 is an important factor in battling infectious agents, including $M$. tuberculosis; therefore it is possible that these individuals through evolution have developed an alternative vitamin D-independent pathway that activates the CAMP gene promoter. This pathway is the activated by endoplasmic reticulum (ER) stress (Steinhoff $e t$ al., 2013; Park et al., 2011; Melnik, 2016).

\section{ENDOPLASMIC RETICULUM STRESS}

ER is a major organelle that is involved in lipid membrane biosynthesis, post-translational protein processing and quality control. It is also an intracellular calcium storage facility. Oxidative stress, as well as unprocessed protein or lipid overload of the ER is followed by an accumulation of misfolded or unfolded proteins. This condition is called ER stress. In order to downplay the misfolded protein load an adaptive mechanism known as the unfolded protein response (UPR) is initiated. As a result, production of GRP78 and GRP94 chaperones occurs and mRNA translation declines. However, it is crucial to mention that translation of 
selected mRNAs, such as activating transcription factor 4 (ATF4) mRNA, is enhanced. All together these are the so called pro-survival mechanisms of UPR. If these mechanisms are not sufficient to combat ER stress, cells switch to autophagy and apoptosis (Sozen and Ozer, 2017). The interplay between ER stress and oxidative stress is complicated. Oxidative stress is more frequently considered as a consequence and mediator of ER stress, rather than the cause (Zeeshan, 2016).

ER stress and rosacea. Majority of rosacea triggers and associated findings can be seen as ER stressors. UV radiation, heat, alcohol consumption, elevated LDL levels, and microorganisms have all been implicated to cause ER stress (Melnik, 2016; Zeeshan et al., 2016; Sozen and Ozer, 2017).

In a recent review a working model of ER stress-centred rosacea pathogenesis has been proposed. ER stress causes increase in sphingosine-1-phosphate (S1P) and ATF4. TLR2 is thought to be upregulated by ATF4. Both S1P and TLR2 activate the pro-inflammatory nuclear factor kappa B $(\mathrm{NF}-\kappa \mathrm{B})$ pathway. Both TLR2 and NF- $\mathrm{KB}$ pathway activate the p38 mitogen-activated protein kinase (p38 MAPK). This causes phosphorylation of a transcription factor known as CCAAT/enhancer-binding protein alpha $(\mathrm{C} / \mathrm{EBP} \alpha)$. Phosphorylated $\mathrm{C} / \mathrm{EBP} \alpha$ binds to a corresponding CAMP promoter region and upregulates the expression of the CAMP gene (Melnik, 2014; 2016). ER stress, in response to heat, can also stimulate TRP channels through S1P signaling, thus potentially causing transient erythema (Mair et al., 2011).

ER stress and atherosclerosis. Several studies have demonstrated upregulation of the UPR mechanisms and therefore signs of ER stress in tissue samples of patients with atherosclerosis. Myoishi et al. performed an interesting study, in which they obtained 70 coronary artery autopsy specimens and 40 atherectomy specimens. VSMCs and macrophages demonstrated increased levels of chaperone expression in specimens with a thin-fibrous-cap atheroma, thus indicating ER stress. The ER stress was induced by 7-ketocholosterol in cultured VSMCs and inhibited by antioxidants, once again pointing out the role of the oxidative stress in atherosclerosis. The authors also described induction of apoptosis as a consequence of ER stress in unstable atherosclerotic plaques (Myoishi et al., 2007). Yet another study acknowledged enhanced ER stress pathways and expression of apoptosis-related genes in the tissue around the necrotic core of the atheroma. This is one of the mechanisms that promotes expansion of the necrotic core (Garbin, 2014).

\section{TOLL-LIKE RECEPTOR 2}

TLR2 is a pathogen pattern recognition receptor that recognises pathogen-associated molecular patterns (PAMPs) and damage-associated molecular patterns (DAMPs). PAMPs are common molecular patterns found on different microor- ganisms that are foreign to our body, such as lipopolysaccharides (LPS) and chitin. DAMPs, on the other hand, are endogenous molecules that are found intracellularly. In case of an injury or cellular stress these molecules can be released, thus activating the innate immunity (Ito, 2014), macrophages and even keratinocytes. Activation of TLR2 can induce pro-inflammatory pathways (De Nardo, 2015). Ethanol - a trigger of rosacea and cardiovascular risk factor when abused - induces inflammation via TLR2 stimulation. TLR2 is expressed by a variety of cells such as endothelial cells, neutrophils (Fernandez-Lizarbe et al., 2013). End products of lipid oxidation have been shown to promote VEGF-independent angiogenesis via stimulation of TLR2. This is an important link between oxidative stress, innate immunity, rosacea, and atherosclerosis (West et al., 2010). TLR2 are also crucial for the activation of MAPK and NF- $\kappa \mathrm{B}$ signalling pathways, leading to increased expression of CAMP (Park et al., 2011; Ji et al., 2014).

Toll-like receptor 2 and rosacea. It has already been mentioned that expression of TLR2 is increased by keratinocytes of rosacea skin. Upon stimulation of TLR2 upregulation of serine protease KLK5 activity is noted in these patients (Yamasaki et al., 2011). Besides end products of lipid oxidation, a possible trigger of the TLR2 is chitin that could be released from Demodex folliculorum mites. These mites are commensal organisms that live in the sebaceous glands, however their density is somewhat increased in patients with rosacea. Besides the chitin that could potentially stimulate TLR2, a bacterium called Bacillus oleronius has been isolated from Demodex mites. Antigenic structure of $B$. oleronius contains heat-shock proteins and lipoproteins that could also stimulate TLR2 (O'Reilly et al., 2012). It is known that abuse of topical glucocorticoids on the facial skin can lead to a development of rosacea-like dermatitis. Interestingly, topical glucocorticoids also cause enhanced production of TLR2 in keratinocytes. This is an additional indicator of the possible role of TLR2 in rosacea pathogenesis (Shibata et al., 2009; Yamasaki et al., 2011). The role of Helicobacter pylori in the pathogenesis of rosacea is controversial. However, some studies state that $H$. pylori infection is more common among rosacea patients, and that certain virulent strains (caA/vacA s1m1 genotypes) are associated with PP rosacea. Eradication of $H$. pylori has been reported to improve the clinical state of rosacea in some studies (Tüzün et al., 2010; Yamasaki et al., 2011; El-Khalawany et al., 2012). It is possible that the treatment improved rosacea symptoms by other mechanisms besides antibacterial. H. pylori infection is associated with increased production of ROS and oxidative stress (Tüzün et al., 2010; Yamasaki et al., 2011; Soundaravally et al., 2013; Two et al., 2015). However, markers of oxidative stress such as increased plasma malondialdehyde (MDA) levels and decreased antioxidant potential (AOP) level, is present rosacea patients independently from H. pylori infection (Baz et al., 2014).

Toll-like receptor 2 and atherosclerosis. Experimental models showed that stimulation of TLR2 promotes develop- 
ment of atherosclerosis in mice. On the other hand, TLR2-deficient mice do not develop atherosclerosis (Mullick et al., 2005). Macrophages in the atherosclerotic plaque overexpress pattern recognition receptors, particularly TLR2 and 4 (Legein et al., 2013). Stimulation of the vascular cells by TLR2 ligands induces expression of proinflammatory cytokines, e.g., the monocyte chemotactic protein - 1 (MCP-1), IL-1 $\alpha$, and IL-1 $\beta$, and provokes development of an atheroma in mice (Lee et al., 2013; Schoneveld et al., 2005). Upon stimulation of TLR2, ROS are produced by NADPH oxidase. These ROS activate matrix metalloproteinase 2 (MMP2) and cause degradation of the extracellular matrix, which in turn induces migration of aortic smooth muscle cells and consequent vascular remodelling. More in depth coverage of the role of ROS in rosacea and atherosclerosis can be found in the text below (Lee et al., 2013; Griendling and Fitzgerald, 2003) Stimulation of TLR2 in the presence of neutrophils promotes ER stress and apoptosis of endothelial cells, thus leading to potential thrombotic complications (Quillard et al., 2015).

\section{OXIDATIVE STRESS}

Reactive oxygen species (ROS) are partly reduced metabolites of oxygen (superoxide anion, hydrogen peroxide and others) that possess high oxidation potential. ROS can be found practically in all cells where they are products of aerobic metabolism and can act as signalling molecules and mediators of inflammation (Förstermann et al., 2017). High concentrations of ROS can also be found in phagocytic cells of the innate immunity, such as macrophages and neutrophils, where they degrade pathogens in collaboration with proteolytic enzymes (Rosales et al., 2016). ROS are primarily generated by enzymes such as nicotinamide adenine dinucleotide phosphate (NADPH) oxidase, cyclooxygenases, xanthine oxidase, peroxidases and the mitochondrial respiratory chain (Sozen and Ozer, 2017).

Antioxidant system consists of an enzymatic component (e.g. superoxide dismutase, catalase) and a non-enzymatic component (e.g. ascorbic acid, alpha-tocopherol, glutathione) that scavenge ROS. Overproduction of ROS and/or impaired antioxidant system leads to the so called oxidative stress. That is known to cause lipid peroxidation, DNA damage and cellular toxicity overall (Goncharov et al., 2015). Oxidative stress is implicated in the pathogenesis of rosacea, atherosclerosis, diabetes and many other diseases. It can also be an overlapping feature between these diseases (Goncharov et al., 2015; Tisma et al., 2009). ROS are capable of inducing inflammation by activating TLR2 and NF- $\kappa$ B pathway (Kelkka et al., 2012; Pateras et al., 2014) ER stress is known to promote production of ROS by various mechanisms, particularly during protein folding and generation of disulfide bonds, however it is not usually seen as a primary ER stressor (Zeeshan et al., 2016).

Oxidative stress and rosacea. Rosacea patients have increased levels of ROS, particularly of serum peroxide levels (Tisma et al., 2009). Medications used to treat rosacea, such as topical metronidazole, azelaic acid and systemic doxycycline, are said to combat oxidative stress (Bakar et al., 2007; Conde et al., 2007; Alikhan, 2010). Facial skin is exposed to solar radiation and it is established that skin exposure to primarily UVA $(320-400 \mathrm{~nm})$ portion of the solar spectrum is responsible for the generation of ROS (Wright et al., 2014). Iron is an important component of cytochromes and oxygen-binding molecules. Free iron molecules can catalyse oxidative reactions, for example conversion of hydrogen peroxide to free radicals, thus promoting oxidative stress. Therefore, iron excesses are bound to ferritin to mitigate oxidative damage to cellular membranes and DNA. It is also known that exposure to UVA may degrade ferritin and release free iron. Accumulation of ferritin is increased in the facial keratinocytes of rosacea skin (Tisma et al., 2009). Additionally, neutrophils are part of the inflammatory infiltrate of rosacea, specifically in the PP subtype (Lee et al., 2016). They are also an important source of ROS (Mittal et al., 2014).

Furthermore, it seems that in patients with rosacea antioxidant system is not efficient - serum total antioxidant potential levels are significantly decreased (Tisma et al., 2009). Superoxide dismutase (SOD) activity is lower in patients with severe rosacea than in healthy controls. This, on the other hand, inversely correlates with increased levels of malondialdehyde (MDA) - a marker of lipid peroxidation (Oztas et al., 2003). Glutathione S-transferases (GSTs) are important players in the defence against ROS, particularly by utilising toxic substances produced by UV-induced oxidative stress. Patients with GST null genotypes have an increased risk of rosacea, probably because of the consequent decrease in the antioxidant potential (Yazici et al., 2006). Serum levels of antioxidant enzyme paraoxonase- 1 are also significantly decreased in individuals with rosacea (Takci et al., 2015).

Oxidative stress may promote development of rosacea in several ways. It has been demonstrated in vitro that ROS may upregulate the expression of TLR2 (Yoshino and Kashiwakura, 2017). ROS promote expression of MMP-1 and MMP-9, thus causing collagen breakdown and remodelling of the extracellular matrix (Liebel et al., 2012). Transient potential receptors that cause flushing erythema in rosacea can sense ROS (Graepel et al., 2011).

Oxidative stress and atherosclerosis. Vascular oxidative stress has a prominent role in atherosclerosis. Cardiovascular risks factors, such as hypertension, diabetes mellitus, dyslipidemia, and smoking, are known to promote production of ROS and inhibit antioxidant systems. There are several possible mechanisms that involve oxidative stress in atherosclerosis (Li and Förstermann, 2014). ROS promote endothelial dysfunction, function as chemoattractants of inflammatory cells, activate platelets, induce proliferation of smooth muscle cells and oxidise atherogenic lipids (Pant et al., 2014).

ROS are linked to the development of the endothelial dysfunction. Nitric oxide (NO) is potent vasodilator that is pro- 
duced in the endothelial cells by the endothelial NO synthase (eNOS). In the case of oxidative stress ROS rapidly scavenge NO. Furthermore, oxidative stress leads to eNOS becoming uncoupled and instead of NO it produces superoxide and peroxynitrite potentiating oxidative stress further (Mittal et al., 2014).

Reactive oxygen species (ROS) and enzymes such as myeloperoxidase (MPO) are responsible for the transformation of LDL into oxLDL. OxLDL is taken up by scavenger receptors, specifically lectin-like oxidised LDL receptor I (LOX-I)) on the endothelium, VSMCs and macrophages. Scavenging of OxLDL by LOX-I causes activation of the NF- $\kappa \mathrm{B}$ pathway, as well as expression of monocyte chemoattractant protein-1 (MCP-1) and vascular cell adhesion molecule-1 (VCAM-1). This promotes attraction and adherence of monocytes that migrate into the subendothelial space. Uptake of the OxLDL by monocyte-derived macrophages results in the formation of foam cells. They are also known to induce proliferation of VSMCs and sometimes their apoptosis. OxLDL induce angiogenesis and secretion of MMPs. Neo-angiogenesis is crucial to sustain growth of the atheroma (Pirillo et al., 2013; Badimon et al. 2012). It is thought that ROS produced via NADPH oxidase are important factors that promote neo-angiogenesis in the atheroma (Kou et al., 2009).

\section{CONCLUSIONS}

It seems that it is not a mere coincidence that rosacea is associated with cardiovascular diseases and their risk factors. Upregulation of TLR2 and CAMP are seen in rosacea and atherosclerosis. Endoplasmic reticulum and oxidative stress are also present in both diseases. The interplay between these pathogenetic mechanisms is complicated and should be studied further. This could potentially lead to a development of new cardiovascular biomarkers and treatment options.

\section{REFERENCES}

Akin Belli, A., Altun, I. (2017). Assessment of Framingham Risk Score and systemic coronary risk evaluation in rosacea patients, Dermatologica Sinica. Available from: https://doi.org/10.1016/j.dsi.2017.03.006 (accessed 17 May 2017).

Alikhan, A., Kurek, L., Feldman, S. R. (2010). The role of tetracyclines in rosacea. Amer. J. Clin. Dermatol., 11 (2), 79-87.

Badimon, L., Padró, T., Vilahur, G. (2012). Atherosclerosis, platelets and thrombosis in acute ischaemic heart disease. Eur. Heart J. Acute Cardiovasc. Care, 1 (1), 60-74.

Bakar, O., Demirçay, Z., Yuksel, M., Haklar, G., Sanisoglu, Y. (2007). The effect of azithromycin on reactive oxygen species in rosacea. Clin. Exp. Dermatol., 32 (2), 197-200.

Baz, K., Cimen, M. Y., Kokturk, A., Aslan, G., Ikizoglu, G., Demirseren, D. D., Kanik, A., Atik, U. (2004). Plasma reactive oxygen species activity and antioxidant potential levels in rosacea patients: Correlation with seropositivity to Helicobacter pylori. Int. J. Dermatol., 43 (7), 494-497.

Benachour, H., Zaiou, M., Samara, A., Herbeth, B., Pfister, M., Lambert, D., Siest, G., Visvikis-Siest, S. (2009). Association of human cathelicidin (hCAP-18/LL-37) gene expression with cardiovascular disease risk factors. Nutr. Metab. Cardiovasc. Dis., 19 (10), 720-728.
Conde, J. F., Yelverton, C. B., Balkrishnan, R., Fleischer, A. B. Jr., Feldman, S. R. (2007). Managing rosacea: A review of the use of metronidazole alone and in combination with oral antibiotics. J. Drugs Dermatol., 6 (5), 495-498.

De Nardo, D. (2015). Toll-like receptors: Activation, signalling and transcriptional modulation. Cytokine, 74 (2), 181-189.

Dombrowski, Y., Peric, M., Koglin, S., Ruzicka, T., Schauber, J. (2010). Control of cutaneous antimicrobial peptides by vitamin D3. Arch. Dermatol. Res., 302 (6), 401-408.

Duman, N., Ersoy Evans, S., Atakan, N. (2014). Rosacea and cardiovascular risk factors: A case control study. J. Eur. Acad. Dermatol. Venereol., 28 (9), 1165-1169.

Edfeldt, K., Agerberth, B., Rottenberg, M. E., Gudmundsson, G. H., Wang, X. B., Mandal, K., Xu, Q., Yan, Z. Q. (2006). Involvement of the antimicrobial peptide LL-37 in human atherosclerosis. Arterioscler. Thromb. Vasc. Biol., 26 (7), 1551-1557.

Egeberg, A., Fowler, J. F. Jr., Gislason, G. H., Thyssen, J. P. (2016). Nationwide assessment of cause-specific mortality in patients with rosacea: A cohort study in Denmark. Amer. J. Clin. Dermatol., 17 (6), 673-679.

Ekiz, O., Balta, I., Sen, B. B., Dikilitaş, M. C., Ozuğuz, P., Rifaioğlu, E. N. (2013). Vitamin D status in patients with rosacea. Cutan. Ocul. Toxicol., 33 (1), 60-62

El-Khalawany, M., Mahmoud, A., Mosbeh, A. S., Alsalam, F., Ghonaim, N., Abou-Bakr, A. (2012). Role of Helicobacter pylori in common rosacea subtypes: A genotypic comparative study of Egyptian patients. $J$. Dermatol., 39 (12), 989-995.

Fernandez-Lizarbe, S., Montesinos, J., Guerri, C. (2013). Ethanol induces TLR4/TLR2 association, triggering an inflammatory response in microglial cells. J. Neurochem, 126 (2), 261-273.

Förstermann, U., Xia, N., Li, H. (2017). Roles of vascular oxidative stress and nitric oxide in the pathogenesis of atherosclerosis. Circ. Res., 120 (4), $713-735$.

Goncharov, N. V., Avdonin, P. V., Nadeev, A. D., Zharkikh, I. L., Jenkins, R. O. (2015). Reactive oxygen species in pathogenesis of atherosclerosis. Curr. Pharm. Des., 21 (9), 1134-1146.

Graepel, R., Fernandes, E. S., Aubdool, A. A., Andersson, D. A., Bevan, S., Brain, S. D. (2011). 4-oxo-2-nonenal (4-ONE): Evidence of transient receptor potential ankyrin 1-dependent and -independent nociceptive and vasoactive responses in vivo. J. Pharmacol. Exp. Ther., 337 (1), 117-124.

Griendling, K. K., FitzGerald, G. A. (2003). Oxidative stress and cardiovascular injury: Part I: basic mechanisms and in vivo monitoring of ROS. Circulation, 108 (16), 1912-1916.

Hansson, G. K., Libby, P. (2006). The immune response in atherosclerosis: A double-edged sword. Nat. Rev. Immunol., 6, 508-519.

Honda, J. R., Connick, E., MaWhinney, S., Chan, E. D., Flores, S. C. (2014). Plasma LL-37 correlates with vitamin D and is reduced in human immunodeficiency virus-1 infected individuals not receiving antiretroviral therapy. J. Med. Microbiol. 63 (Pt 7), 997-1003.

Hua, T. C., Chung, P. I., Chen, Y. J., Wu, L. C., Chen, Y. D., Hwang, C. Y., Chu, S. Y., Chen, C. C., Lee, D. D., Chang, Y. T., Liu, H. N. (2015). Cardiovascular comorbidities in patients with rosacea: A nationwide case-control study from Taiwan. J. Amer. Acad. Dermatol., 73 (2), 249-254.

Ito, T. (2014). PAMPs and DAMPs as triggers for DIC. J. Intensive Care, 2 (1), 67.

Jaipersad, A. S., Lip, G. Y., Silverman, S., Shantsila, E. (2014). The role of monocytes in angiogenesis and atherosclerosis. J. Amer. Coll. Cardiol., 63 (1), 1-11.

Ji, L, Xue, R., Tang, W., Wu, W., Hu, T., Liu, X., Peng, X., Gu, J., Chen, S., Zhang, S. (2014). Toll like receptor 2 knock-out attenuates carbon tetrachloride (CCl4)-induced liver fibrosis by downregulating MAPK and NF-źB signaling pathways. FEBS Lett., 588 (12), 2095-2100. 
Kassi, E., Adamopoulos, C., Basdra, E.K., Papavassiliou, A.G. (2013). Role of vitamin D in atherosclerosis. Circulation, 128 (23), 2517-2531.

Kelkka, T., Hultqvist, M., Nandakumar, K. S., Holmdahl, R. (2012). Enhancement of antibody-induced arthritis via Toll-like receptor 2 stimulation is regulated by granulocyte reactive oxygen species. Amer. J. Pathol., 181 (1), 141-150.

Kou, B., Zhang, J., Singer, D. R. (2009). Effects of cyclic strain on endothelial cell apoptosis and tubulogenesis are dependent on ROS production via NAD(P)H subunit p22phox. Microvasc. Res., 77 (2), 125-133.

Lee, J. H., Joo, J. H., Kim, J., Lim, H. J., Kim, S., Curtiss, L., Seong, J. K., Cui, W., Yabe-Nishimura, C., Bae, Y. S. (2013). Interaction of NADPH oxidase 1 with Toll-like receptor 2 induces migration of smooth muscle cells. Cardiovasc. Res., 99 (3), 483-493.

Lee, W. J., Jung, J. M., Lee, Y. J., Won, C. H., Chang, S. E., Choi, J. H., Moon, K. C., Lee, M. W. (2016). Histopathological analysis of 226 patients with rosacea according to rosacea subtype and severity. Amer. J. Dermatopathol., 38 (5), 347-352.

Legein, B., Temmerman, L., Biessen, E. A., Lutgens, E. (2013). Inflammation and immune system interactions in atherosclerosis. Cell Mol. Life Sci., 70 (20), 3847-3869.

Li, H., Horke, S., Förstermann, U. (2014). Vascular oxidative stress, nitric oxide and atherosclerosis. Atherosclerosis, 237 (1), 208-219.

Liebel, F., Kaur, S., Ruvolo, E., Kollias, N., Southall, M. D. (2012). Irradiation of skin with visible light induces reactive oxygen species and matrix-degrading enzymes. J. Invest. Dermatol., 132 (7), 1901-1907.

Litman, G. W., Cannon, J. P., Dishaw, L. J. (2005). Reconstructing immune phylogeny: New perspectives. Nat. Rev. Immunol., 5 (11), 866-879.

Mair, N., Benetti, C., Andratsch, M., Leitner, M. G., Constantin, C. E., Camprubí-Robles, M., Quarta, S., Biasio, W., Kuner, R., Gibbins, I. L., Kress, M., Haberberger, R. V. (2011). Genetic evidence for involvement of neuronally expressed $\mathrm{S}_{1} \mathrm{P}_{1}$ receptor in nociceptor sensitization and inflammatory pain. PLoS One, 6 (2), e17268.

Melnik, B. C. (2014). Endoplasmic reticulum stress: Key promoter of rosacea pathogenesis. Exp. Dermatol., 23 (12), 868-873.

Melnik, B. C. (2016). Rosacea: The blessing of the Celts. An approach to pathogenesis through translational research. Acta Derm. Venereol., 96 (2), $147-156$.

Mendis, S., Davis, S., Norrving, B. (2015). Organizational update: The World Health Organization global status report on noncommunicable diseases 2014; one more landmark step in the combat against stroke and vascular disease. Stroke, 46 (5), e121-2

Mittal, M., Siddiqui, M. R., Tran, K., Reddy, S. P., Malik, A. B. (2014). Reactive oxygen species in inflammation and tissue injury. Antioxid. Redox. Signal., 20 (7), 1126-1167.

Mullick, A. E., Tobias, P. S., Curtiss, L. K. (2005). Modulation of atherosclerosis in mice by Toll-like receptor 2. J. Clin. Invest., 115 (11), 3149-3156.

Myoishi, M., Hao, H., Minamino, T., Watanabe, K., Nishihira, K., Hatakeyama, K., Asada, Y., Okada, K., Ishibashi-Ueda, H., Gabbiani, G., Bochaton-Piallat, M. L., Mochizuki, N., Kitakaze, M. (2007). Increased endoplasmic reticulum stress in atherosclerotic plaques associated with acute coronary syndrome. Circulation, 116 (11), 1226-1233.

O'Reilly, N., Menezes, N., Kavanagh, K. (2012). Positive correlation between serum immunoreactivity to Demodex-associated Bacillus proteins and erythematotelangiectatic rosacea. Brit. J. Dermatol., 167 (5), 1032-1036.

Oztas, M. O., Balk, M., Ogüs, E., Bozkurt, M., Ogüs, I. H., Ozer, N. (2003). The role of free oxygen radicals in the aetiopathogenesis of rosacea. Clin. Exp. Dermatol., 28 (2), 188-192.

Pant, S., Deshmukh, A., Gurumurthy, G. S., Pothineni, N. V., Watts, T. E., Romeo, F., Mehta, J. L. (2014). Inflammation and atherosclerosis - revisited. J. Cardiovasc. Pharmacol. Ther., 19 (2),170-178.
Park, K., Elias, P. M., Oda, Y., Mackenzie, D., Mauro, T., Holleran, W. M., Uchida, Y. (2011). Regulation of cathelicidin antimicrobial peptide expression by an endoplasmic reticulum (ER) stress signaling, vitamin D receptor-independent pathway. J. Biol. Chem., 286 (39), 34121-34130.

Pateras, I., Giaginis, C., Tsigris, C., Patsouris, E., Theocharis, S. (2014) $\mathrm{NF}-\kappa \mathrm{B}$ signaling at the crossroads of inflammation and atherogenesis: Searching for new therapeutic links. Expert Opin. Ther. Targets, 18 (9), 1089-1101.

Pirillo, A., Norata, G. D., Catapano, A. L. (2013). LOX-1, OxLDL, and atherosclerosis. Mediators Inflamm., 2013, 152786.

Quillard, T., Araśjo, H. A., Franck, G., Shvartz, E., Sukhova, G., Libby, P. (2015). TLR2 and neutrophils potentiate endothelial stress, apoptosis and detachment: implications for superficial erosion. Eur. Heart J., 36 (22), 1394-1404.

Reinholz, M., Ruzicka, T., Schauber, J. (2012). Cathelicidin LL-37: An antimicrobial peptide with a role in inflammatory skin disease. Ann. Dermatol., 24 (2), 126-135.

Rosales, C., Demaurex, N., Lowell, C. A., Uribe-Querol, E. (2016) Neutrophils: Their role in innate and adaptive immunity. J. Immunol. Res., 2016 1469780.

Salvado, M. D., Di Gennaro, A., Lindbom, L., Agerberth, B., Haeggström, J. Z. (2013). Cathelicidin LL-37 induces angiogenesis via PGE2-EP3 signaling in endothelial cells, in vivo inhibition by aspirin. Arterioscler. Thromb. Vasc. Biol., 33 (8), 1965-1972.

Schoneveld, A. H., Oude Nijhuis, M. M., van Middelaar, B., Laman, J. D., de Kleijn, D. P., Pasterkamp, G. (2005). Toll-like receptor 2 stimulation induces intimal hyperplasia and atherosclerotic lesion development. Cardiovasc. Res., 66 (1), 162-169.

Shibata, M., Katsuyama, M., Onodera, T., Ehama, R., Hosoi, J., Tagami, H. (2009). Glucocorticoids enhance Toll-like receptor 2 expression in human keratinocytes stimulated with Propionibacterium acnes or proinflammatory cytokines. J. Invest. Dermatol., 129 (2), 375-382.

Soundaravally, R., Pukazhvandthen, P., Zachariah, B., Hamide, A. (2013). Plasma ferritin and indices of oxidative stress in Helicobacter pylori infection among schoolchildren. J. Pediatr. Gastroenterol. Nutr., 56 (5), 519-522.

Sozen, E., Ozer, N. K. (2017). Impact of high cholesterol and endoplasmic reticulum stress on metabolic diseases: An updated mini-review. Redox Biol., 12, 456-461.

Spoendlin, J., Voegel, J. J., Jick, S. S., Meier, C. R. (2012). A study on the epidemiology of rosacea in the U.K. Brit. J. Dermatol., 167 (3), 598-605.

Steinhoff, M., Schauber, J., Leyden, J. J. (2013). New insights into rosacea pathophysiology: A review of recent findings. J. Amer. Acad. Dermatol., 69 (6 Suppl. 1), S15-26.

Steinhoff, M., Schmelz, M., Schauber, J. (2016). Facial erythema of Rosacea: aetiology, different pathophysiologies and treatment options. Acta Derm. Venereol., 96 (5), 579-586.

Takci, Z., Bilgili, S. G., Karadag, A. S., Kucukoglu, M. E., Selek, S., Aslan, M. (2015). Decreased serum paraoxonase and arylesterase activities in patients with rosacea. J. Eur. Acad. Dermatol. Venereol., 29 (2), 367-370.

Tisma, V. S., Basta-Juzbasic, A., Jaganjac, M., Brcic, L., Dobric, I., Lipozencic, J., Tatzber, F., Zarkovic, N., Poljak-Blazi, M. (2009). Oxidative stress and ferritin expression in the skin of patients with rosacea. $J$. Amer. Acad. Dermatol., 60 (2), 270-276.

Tüzün, Y., Keskin, S., Kote, E. (2010). The role of Helicobacter pylori infection in skin diseases: Facts and controversies. Clin. Dermatol., 28 (5), $478-482$.

Two, A. M., Wu, W., Gallo, R. L., Hata, T. R. (2015). Rosacea: Part I. Introduction, categorization, histology, pathogenesis, and risk factors. J. Amer. Acad. Dermatol., 72 (5), 749-758; quiz 759-760.

West, X. Z., Malinin, N. L., Merkulova, A. A., Tischenko, M., Kerr, B. A., Borden, E. C., Podrez, E. A., Salomon, R. G., Byzova, T. V. (2010). Oxida- 
tive stress induces angiogenesis by activating TLR2 with novel endogenous ligands. Nature, 467 (7318), 972-976.

Wilkin, J., Dahl, M., Detmar, M., Drake, L., Feinstein, A., Odom, R., Powell, F. (2002). Standard classification of rosacea: Report of the National Rosacea Society Expert Committee on the Classification and Staging of Rosacea. J. Amer. Acad. Dermatol., 46 (4), 584-587.

Wright, J. A., Richards, T., Srai, S. K. (2014). The role of iron in the skin and cutaneous wound healing. Front Pharmacol. 5, 156.

Yamasaki, K., Di Nardo, A., Bardan, A., Murakami, M., Ohtake, T., Coda, A., Dorschner, R. A., Bonnart, C., Descargues, P., Hovnanian, A., Morhenn, V. B., Gallo, R. L. (2007). Increased serine protease activity and cathelicidin promotes skin inflammation in rosacea. Nat. Med., 13 (8), 975-980.

Received 11 July 2017

Accepted in the final form 15 January 2018
Yamasaki, K., Gallo, R. L. (2009). The molecular pathology of rosacea. $J$. Dermatol. Sci., 55 (2), 77-81.

Yamasaki, K., Kanada, K., Macleod, D. T., Borkowski, A. W., Morizane, S., Nakatsuji, T., Cogen, A. L., Gallo, R. L. (2011). TLR2 expression is increased in rosacea and stimulates enhanced serine protease production by keratinocytes. J. Invest. Dermatol., 131 (3), 688-697.

Yazici, A. C., Tamer, L., Ikizoglu, G., Kaya, T. I., Api, H., Yildirim, H., Adiguzel, A. (2006). GSTM1 and GSTT1 null genotypes as possible heritable factors of rosacea. Photodermatol. Photoimmunol. Photomed., 22 (4), 208-210.

Yoshino, H., Kashiwakura, I. (2017). Involvement of reactive oxygen species in ionizing radiation-induced upregulation of cell surface Toll-like receptor 2 and 4 expression in human monocytic cells. J. Radiat. Res., 22, $1-10$.

Zeeshan, H. M., Lee, G. H., Kim, H. R., Chae, H. J. (2016). Endoplasmic reticulum stress and associated ROS. Int. J. Mol. Sci., 17 (3), 327.

\section{ROZĀCIJAS UN ATEROSKLEROZES PATOGENĒZES KOPĪGĀS IEZĪMES}

Rozācija ir hroniska iekaisīga ādas slimība, kas skar sejas centrālos apvidus. Raksturīgs pastāvīgs un pārejošs apsārtums, telangiektāzes un papulopustulozi izsitumi. Jaunākie pētījumi norāda uz saistību starp rozāciju un sirds un asinsvadu saslimšanām (SAS). Rozācijas un aterosklerozes pacientiem novēro iedzimtās imunitātes novirzes, oksidatīvo un endoplazmatiskā tīkla stresu. Šì apskata raksta mērkis ir padziḷināti izpētìt abu saslimšanu patoǵenēzi un atklāt iespējamās līdzības starp šīm hroniskām, iekaisīgām slimībām. 